\title{
Research on the Evaluation and Promotion of Employees from the Perspective of Competency
}

\author{
Xiaojuan Chang, Jian Xue \\ Shaanxi University of Science and Technology, Xi'an, China \\ Email:413795562@qq.com
}

How to cite this paper: Chang, X. J., \& Xue, J. (2020). Research on the Evaluation and Promotion of Employees from the Perspective of Competency. Open Journal of Social Sciences, 8, 99-108. https://doi.org/10.4236/jss.2020.82009

Received: January 17, 2020

Accepted: February 21, 2020

Published: February 24, 2020

Copyright $\odot 2020$ by author(s) and Scientific Research Publishing Inc. This work is licensed under the Creative Commons Attribution International License (CC BY 4.0).

http://creativecommons.org/licenses/by/4.0/

\begin{abstract}
With the gradual deepening of economic globalization, it has brought opportunities and challenges to the development of Chinese private enterprises. Under the new situation, the private employees of developing private enterprises have encountered problems such as lack of ability, lack of technology, and lack of initiative, which hindered the realization of corporate development strategies and inhibited the competitive vitality of enterprises. At the most basic level of the enterprise, its overall ability has an important role in the production and sustainable development of the enterprise. Therefore, evaluation and efforts to improve the ability of the basic level employees have become the focus of enterprise development. After the 1970s, scholars represented by McClelland proposed the "competency model" for employee training, and formulated corresponding human resource management methods by quantifying employee competence. With the competency model, the performance of employees in specific positions can be clearly displayed, which is an important criterion for judging the work willingness and ability of employees. This article takes Company A as an example, and takes the company's workshop employees as the research object. It summarizes issues such as the development of competence theory at home and abroad, the determination of competency concepts, and an overview of competency models, as well as a study of the production and operation status of Company A. Based on the four key elements of the competency model: motivation, traits, self-concept, and social role, based on the actual situation of Company A, combined with questionnaires, factor analysis and other related research methods, it proposed that Company A's ability to improve employees. The development path is intended to solve the production and operation dilemma of Company A and promote the flexible application of the competency model in the modernization process of the textile industry.
\end{abstract}

\section{Keywords}

Competency Model, Textile Industry, Workshop, Factor Analysis 


\section{Introduction}

Since the forty years of reform and opening up, private enterprises have driven China's economic growth and are a vital force in the development of the national economy. They have played an important role in stabilizing growth, promoting innovation, increasing employment, and improving people's livelihood. With the gradual deepening of the process of economic globalization, the development of China's private enterprises has brought development opportunities and severe challenges. Under the new situation, private enterprises have encountered some problems in the development, such as low ideological and moral qualities of employees, lack of work ability, lack of technical level, insufficient initiative and creativity, etc., which are mainly manifested in the textile and apparel, housekeeping, medical, and education industries, hinder the realization of corporate development strategies, and also inhibit the competitive vitality of enterprises. At the most basic level of the enterprise, its overall ability plays an important role in the production and sustainable development of the enterprise. In the textile industry, workshop employees are the key cultivation objects of enterprises, and their capabilities are related to the overall development of textile enterprises. The employee evaluation mechanism can stimulate employees' work enthusiasm and improve the overall competitiveness of the enterprise. Therefore, objectively evaluating and improving the ability of private employees at the grass-roots level are an urgent problem in the development of private enterprises in our country. This article takes the employees of Company A as the research object and summarizes the relevant theories of competence by scholars at home and abroad through a literature review. Competency evaluation system construction and other aspects are studied, and then the questionnaire survey method is used to analyze and evaluate the current status of the competencies of company A's workshop employees, find out the current problems of company A's managerial competency evaluation, and propose related improvement countermeasures.

\subsection{Analysis of Employee Status}

Enterprise A is a private enterprise mainly in the textile industry, which is a typical labor-intensive enterprise. The company has a total of 517 employees, of which 308 are productive employees. The company mainly produces production technicians, and it has low requirements for related knowledge and professionalism in textile production. In addition, there are corresponding operating guidelines for production-related links. On the whole, the qualifications and qualifications of employees are not very strict. From the perspective of the distribution of academic qualifications, the higher the level of educational qualifications, the smaller the number, showing a decreasing trend. The age distribution of employees accounts for a relatively high number of middle-aged laborers. This part of the employees is an important force for enterprise development, and it is their existence that maintains the normal operation of the workshop and ensures the 
completion of the company's production goals.

\subsection{Analysis of the Competence of Workshop Employees}

\subsubsection{Problems with Post Capabilities}

The ability of company A's workshop staff lagged behind other enterprises in the same industry. The company is dominated by old employees, leading to the lack of vitality of the company. The job capacity of workshop employees focuses on job technical operation capabilities, neglecting the improvement of other capabilities, and more attention is paid to the training of employees "post skills. Little consideration is given to employees" careers and job-specific occupations. The basic situation of development sets out comprehensive capacity requirements.

\subsubsection{Problems in Production Efficiency}

The overall production efficiency of the workshop is relatively low, the technology update is slow, and the hardware configuration level of the workshop has gradually fallen behind. At the same time, employees are accustomed to old production equipment, lack of learning and training for new equipment, and it takes a long time to train, causing technology. The difficulty of innovation has greatly reduced production efficiency. Judging from the enthusiasm of employees, most of the old employees who are accustomed to the traditional assessment methods have not been able to complete the change of thinking mode. They still maintain a working mentality of completing the specified number of pieces and going to work on time and on time. It is difficult to create higher production performance.

\subsubsection{Problems in the Training System}

Workshop staff training system is not complete and training efficiency is not high. The time and content of staff training need to be improved. The personnel trained in the company are fixed and minority, and rarely can they improve their technical level and post quality through professional training. The content focuses on the sharing and popularization of technical knowledge, and ignores the training of teamwork spirit, innovation ability, contingency ability and execution ability. For workshop employees, the requirements of the post for employees are not only the proficiency of equipment operation and technical knowledge, but also the comprehensive quality of other aspects of the employees, resulting in overall training effectiveness is not strong.

\section{Literature Review}

The emergence of the concept of competence is inseparable from the improvement of the industrialization of human society. After the Industrial Revolution, human society has gradually entered the era of large industries, and labor-intensive enterprises represented by the textile industry and processing industry have risen rapidly. The differences in the quality and level of work among workers have gradually been valued by management scholars. 
Harvard management professor David McClelland further elaborated the meaning of competence in his research. In his article "Testing for Competency Rather Than Intelligence" published in the American Psychologist, he pointed out that there are inherent flaws in the traditional assessment model of workers' capabilities. "Competency" must be the core element for evaluating employees' ability to perform at work. This is because competence includes the most core conditions and behavioral characteristics that can really affect employees' job performance. Only those elements that can significantly distinguish job performance are the only criteria for judging competency. In addition, Professor McClelland also believes that judging the quality and level of work of employees through competence must be based on objective data to minimize the impact of subjective judgments and ensure the scientific and objective evaluation results.

Management scholars Hamill and Prahalad based on the concept of competence and published a paper entitled "Company Core Competence." In this article, they extended the concept of competence in the personal dimension and applied it to the company's organizational structure. They tried to build a company's human resource management framework of "workers-posts-departments" and creatively will be competent the concept of force was introduced into a new area of corporate management. Through the summary analysis of the academic viewpoints, there are some commonalities in the definition of competence both at home and abroad.

First of all, competency is not a single-dimensional element, but a collection of multiple elements. The most common motivations, knowledge, personal characteristics, and skills appear in the collection. Therefore, when studying employee competence, these elements need to be considered. Second, the concept of competence is an open, constantly evolving concept. In combination with the development experience of domestic enterprises, in addition to some common elements in the concept of competence, individual elements will also be covered depending on the industry. The concept of competence has a certain personal color, and the meaning of competence may be different for different people. Therefore, from the perspective of competence, the analysis of employees "capabilities must be closely integrated with all aspects of employees" lives to draw as practical conclusions as possible.

From the perspective of classification, the elements included in the competency model can be divided into two categories, the first category is for ordinary employees, and the second category is for middle and senior management personnel. To analyze the ability training of company A's workshop employees based on the competency model, it is necessary to analyze not only the competency model itself, but also the characteristics of the ability of the workshop employees themselves.

Guo Yu (2019) pointed out in his research that the comprehensive ability of employees in the production workshop not only affects the company's application efficiency of technology and equipment, but also affects the company's 
overall production efficiency and product quality. poor professional skills and lack of sense of responsibility in the production process. At the same time, the cooperation between employees is not in place, and prone to lack of communication and unreasonable operations. Production equipment causes unnecessary losses, and will also reduce the production efficiency of the enterprise and increase the input cost of the enterprise.

Zhu Jia (2019) pointed out in his research that the quality of employees largely determines the production efficiency and quality level of an enterprise. At present, workshop employees in labor-intensive industries generally lack due professional knowledge and understanding, and their ability to adapt and learn is generally poor. When faced with the update of corporate management concepts and business concepts, it is difficult to quickly accept them, making new production of enterprises Cost methods are difficult to implement effectively, and development in the past will be constrained.

Chang Yanfeng (2019) divided the employees of the production workshop into four categories based on their duties and responsibilities as the standard: the first category is the basic staff, which accounts for three quarters of the entire workshop; the remaining three categories are respectively It is grassroots management staff, middle management staff, and senior leadership, which accounts for a quarter of the total number of employees in the workshop. From the perspective of personnel distribution, the basic staff is concentrated in the production area of the workshop, including production personnel, quality inspection and monitoring personnel, product distribution personnel, and security inspectors. Judging from the level of education, most of these grassroots staff do not have a bachelor's degree, and most of them only have junior high school or college education level. In addition, because these grassroots workers have been engaged in mechanical production for a long time, the inertia and inertia formed in the process also make it difficult for them to accept the company's new management philosophy and business philosophy, which has caused the innovation of the company's overall management level Hinder.

Combining the above-mentioned domestic and foreign studies, we can find that the current domestic and foreign research on the competency model and the ability of workshop employees has the following characteristics:

First, in the study of competency models, emphasis is placed on theory and practice. Whether at home or abroad, most of the current research on the competency model is still on the exploration of the concept of competency and the connotation of the competency model. Because the competency model is mainly used in the specific production and management of enterprises, Just relying on theoretical research can easily cause a disconnect between theory and practice. Most of the existing competency model studies have tended to stagnate after proposing the connotation of the competency model, and no constructive opinions have been put forward for the current management of Chinese enterprises on this basis. In addition, even if a few studies try to build a model from theory 
to practice, most of them ignore the gap between different production industries, making these suggestions formal, lacking practicality and pertinence.

Second, there is a large gap in domestic and foreign research on the capabilities of workshop employees. Due to China's special national conditions, the development of labor-intensive industries is different from the overall development of the world. Therefore, foreign studies on the work ability of workshop employees are not of sufficient significance to China. Secondly, due to the influence of different industrial structures at home and abroad, even if they are also workshop employees, domestic workshop employees and foreign workshop employees are greatly different in terms of vocational skills, education level, and learning ability.

\section{Methodology}

The main purpose of this study to build the competency model is to summarize the factors that affect the work ability and quality of the employees of company A's workshop, and try to establish a systematic, scientific, and accurate employee competency evaluation system. Provide guidance for the follow-up company A's workshop employees to improve their working ability and quality, and explore new ideas for employee ability training. When screening the elements of competence, the literature research method and behavioral event interview method were mainly used. On the basis of these two methods, the competence factors in McClelland's "Competency Dictionary" were further analyzed and verified, and finally the relevant elements of the competency model in this paper were adjusted.

\subsection{Apply Literature Research}

The research results of $\mathrm{G}$ textile company sales representative competency model construction, A province $S$ city textile enterprise workshop employee competency model construction, B city human resources consulting company's related survey of the textile industry competence are summarized, and company A is comprehensive The characteristics of the corporate culture and industry in the region are excluded from the McClelland's "Competent Quality Dictionary", which are inconsistent with the actual operating conditions of Company A.

\subsection{Use Behavioral Event Interview Method}

Through structured communication with ordinary employees, grass-roots managers, and middle-level managers in the workshop of Company A, ordinary employees are required to review the typical events and real cases that have occurred since they entered the workshop of Company A, and evaluate their own competence; grass-roots management is required Personnel and middle management personnel shall explain the evaluation results and evaluation reasons of their employees under the evaluation form submitted each month, and evaluate the employees' competence. 


\subsection{Design the Questionnaire}

Overall, 308 questionnaires sent out by the 308 workshop employees surveyed this time totaled 308 questionnaires, and the number of valid questionnaires was 297. The basic information is shown in Table 1 .

Determine the questionnaire parameters. This study involved employees "assessment of their own competence and the assessment of others" competence. In the evaluation criteria, a Likert scale was selected to enable respondents to conduct "very important" questions on competence on the questionnaire. -More important-generally important-less important-not important "judgment, according to such judgments to score each competency element. The average of the scores of the six competency elements was sorted, followed by analysis and processing of the standard deviation, and combined with the results of the previous analysis, the results of the questionnaire analysis are shown in Table 2.

By investigating the factors affecting the work quality and work level of company A's workshop employees, combining the company's corporate culture, corporate development strategy, and the development direction of the entire textile industry market in the future, the performance standards of company A's

Table 1. Workshop employee basic information form.

\begin{tabular}{cccc}
\hline Dimensions & - & People & Proportion \\
\hline Gender & Male & 54 & $18 \%$ \\
\multirow{2}{*}{ Age } & Female & 254 & $82 \%$ \\
& $20-30$ years & 93 & $30 \%$ \\
& 31 - 40 years & 114 & $37 \%$ \\
& $41-50$ years old & 96 & $31 \%$ \\
Working years & Above 50 years old & 5 & $2 \%$ \\
& up to 3 years & 65 & $21 \%$ \\
& 3 years - 5 years & 82 & $27 \%$ \\
& 5 years - 10 years & 114 & $37 \%$ \\
& More than 10 years & 47 & $15 \%$ \\
\hline
\end{tabular}

Table 2. Questionnaire analysis results form.

\begin{tabular}{ccccc}
\hline $\begin{array}{c}\text { Importance } \\
\text { number } \\
\text { (High-Low) }\end{array}$ & $\begin{array}{c}\text { Competency } \\
\text { Factors }\end{array}$ & $\begin{array}{c}\text { Total } \\
\text { Score }\end{array}$ & $\begin{array}{c}\text { Average Score } \\
\text { (Keep two decimal } \\
\text { places) }\end{array}$ & $\begin{array}{c}\text { Standard deviation } \\
\text { (Keep two decimal } \\
\text { places) }\end{array}$ \\
\hline C1 & motivation & 1342 & 5.52 & 0.75 \\
C2 & Traits & 1309 & 4.41 & 0.89 \\
C3 & Self Concept & 1298 & 4.37 & 0.88 \\
C4 & Social Role & 1254 & 4.22 & 0.73 \\
C5 & skill & 1243 & 4.19 & 0.92 \\
C6 & Knowledge & 1232 & 4.15 & 0.95 \\
\hline
\end{tabular}


workshop employees were evaluated Confirm, and then complete the steps of sample selection, data analysis, expert interviews and inspections to achieve the construction of the competency model.

\section{Conclusions and Recommendations}

The textile workshop evaluates the employee's competence in order to help the company find the best candidate, and at the same time, the employees can also improve their self-abilities. The two can promote each other and grow with each other, which is ultimately beneficial to the development of the enterprise and the ultimate goal of enterprise development.

\subsection{Analyze Employee Training Needs and Formulate Specific Training Programs}

1) Based on the competency model, first quantitative and qualitative analysis of employee training needs should be conducted. First, a series of tests were conducted on the current strengths and weaknesses of company A's workshop employees in their competencies, their desire for achievement, their responsibility for innovation and creativity, four types of personality temperament, communication skills, self-awareness and self-evaluation. The specific analysis results are shown in Table 3.

Among the factors affecting employee competence, the motivation component has the highest importance, but also has the highest degree of lack. Employees generally lack a lack of awareness of their social status and role. However, traits and self-concepts, as the other two major factors affecting competence, are still in general in the current state of company A's workshop employees, and need to be compensated through employee training.

2) Based on the analysis results, a training plan needs to be developed.

The job capacity training scale should be re-determined for company A's workshop employees, and the methods that help improve the competency of employees should be listed, such as: external exchange training, internal training of external lecturers, mutual assistance of employee groups, mentor tracking and coaching, daily science and technology. Daily science and technology lectures, micro-learning platform, etc., researched on the specific channels, advantages, and disadvantages of the six employees' job capacity training methods, and came

Table 3. Test results analysis table.

\begin{tabular}{|c|c|c|c|}
\hline Element & $\begin{array}{l}\text { Competence } \\
\text { weight in job } \\
\text { training }\end{array}$ & $\begin{array}{c}\text { Level of employee } \\
\text { deficiencies (based on } \\
\text { Likert scale) }\end{array}$ & Staff training planning steps \\
\hline motivation & $28.314 \%$ & 5 (very lacking) & \multirow{4}{*}{$\begin{array}{l}\text { 1) Analyze the causes of gaps and } \\
\text { obtain training needs. } \\
\text { 2) Specify targeted training programs. } \\
\text { 3) Promote and supervise the } \\
\text { implementation of the plan. }\end{array}$} \\
\hline traits & $25.863 \%$ & 3 (Generally lacking) & \\
\hline self-concept & $16.729 \%$ & 3 (Generally lacking) & \\
\hline social role & $14.532 \%$ & 2 (Not too lacking) & \\
\hline
\end{tabular}


to a conclusion. For the training of Company A's workshop employees, the training of employees should be flexibly combined with the advantages. The advantages, disadvantages, and competencies of the method are focused, and employee training is carried out flexibly. In the daily training process, it is necessary to pay attention to the needs of employees as well as strengthen the scientific literacy of employees, so that employees can receive advanced science and technology in the textile industry as soon as possible, and promote the modernization and technology of the production chain of Company A's workshop.

\subsection{Improve the Recruitment Mechanism and Select Employees That Match the Position of the Company}

To improve the recruitment mechanism, it is necessary to plan the entire recruitment system of Company A. From the perspective of recruitment methods, we can cooperate with local governments. In order to promote the overall development of the local light industry and heavy industry, the government incorporates the job motivation, personal characteristics, self-recognition, and social status of candidates into the scope of recruitment assessment in conjunction with the competency model, and uses the authority of the government to conduct a series of corporate recruitment announcements.. The use of Internet technology, combined with the local talent market, broadened the scope of online recruitment. Establish a matching recruitment review mechanism, the website background and the HR recruitment mailbox are regularly synchronized to simplify the recruitment process and save recruitment costs. Optimize the way to recruit technology talents. You can continue to use the traditional recruitment method to ensure that there will not be a large number of brain drain. You can also strengthen school-enterprise cooperation and attract outstanding graduates. You can also choose colleges and universities to cooperate, invest some funds and technology, and establish a textile industry incubation base. Stimulate students' enthusiasm for learning, and combine certain employment preferential policies to attract graduates.

\subsection{Improve the Company's Management Rules and Regulations and Enhance Implementation}

Strengthen the learning of management concepts of company A's workshop employees, and by disseminating advanced textile industry management concepts to employees, make employees gradually understand the original intention of the company's management, and then dissolve the psychological gap between employees and company management. Encourage and urge employees to put forward suggestions for improving the company's management rules and regulations, so that employees become the formulator, executor, and supervisor of the company's rules and management systems, so as to improve the implementation of management company A's workshop employees' management accountability affairs. Actively learning the experience of advanced domestic and foreign enterprises in the construction of management rules and regulations. Select the 
employees with high education level, initiative and strong learning ability in the workshop, give them certain management rights, establish a workshop technical person in charge system, so that advanced employees can take the lead, and promote the improvement of the execution of the entire workshop.

In summary, an effective employee competency evaluation mechanism is of great significance for improving the overall competitiveness of the enterprise and its future development. With the rapid development of the modern knowledge-based economy, diversification and comprehensiveness of talents are increasingly required. From the perspective of the competence of employees in textile workshops, to enhance the value of research results, it is necessary to comprehensively analyze, including Production competence and organizational competence. For enterprises, it is necessary to improve the company's management rules and regulations, strengthen the study of management concepts, establish a sense of rules and contractual spirit, ensure the team's implementation, and strengthen the emphasis on employee training. Professional team, create a complete staff evaluation mechanism, to the maximum extent to train enterprises for comprehensive development of personnel, and provide important personnel support.

\section{Conflicts of Interest}

The authors declare no conflicts of interest regarding the publication of this paper.

\section{References}

Chang, Y. F. (2019). Application of Project Management Team in Human Resource Management of Enterprise Workshop. Enterprise Reform and Management, No. 9, 84-85.

Guo, Y. (2019). Talking about How to Reduce Costs and Increase Efficiency in Production Workshops of Large Enterprises. Internal Combustion Engines and Parts, No. 13, 220-221.

Zhu, J. (2019) Application Value of Target Management in Workshop Cost Control. Finance and Accounting Study, No. 7, $149+151$. 